of "very curious meteorological instruments of a new and ingenuous construction ". The book had a great vogue, passing through thirty editions.

Adams was essentially a mechanic and delighted in good workmanship. There can be little doubt, I think, that the microscope was his favourite instrument, and he developed several types of it. In 1746 he published his "Micrographia Illustrata : or The Knowledge of the Microscope explained in several new inventions etc.". The preface to the "Micrographia Illustrata" emphasises the religious side of Adams's character, and also shows that he must have had the artistic and poetic temperament highly developed. The first edition of the book contained an account of a "New Universal Microscope" which was made to an entirely original design, the object being, as Adams states, "to have a Microscope which would be Portable and Universal, that is to say, ONE ONLY INSTRUMENT, by which all Sorts of minute Objects might be observ'd". The microscope was provided with six single lenses of different foci with a common focusing screw. Adams remarked of this focusing screw that it "is to be turned as your hands and arms are resting on the table, which is a conveniency to be met with in no other
Microscope". A second edition of the "Micrographia Illustrata " appeared in 1747, and a fourth in 1771. Despite exhaustive researches it has not been possible to find a copy of the third edition-if it were ever published.

The fourth edition commences with a description of the variable microscope of which Adams was evidently very proud. He states that "We owe the construction of the Variable Microscope to the ingenuity and generosity of a noble person ", and we know that the "noble person" was the Earl of Bute. By having a compound eye lens and by introducing an auxiliary lens placed some distance above the objective the definition was improved. Adams also introduced the method of screwing two or three objective lenses one on top of the other. By drawing up the eyepiece relative to the object glass the power of the combination could be altered and hence the name "variable". Adams, in common with Martin and other makers of the period, developed the solar microscope with the large mirror projecting out of the window, by means of which brilliant illumination could be obtained, and magnified images of the object projected on to a screen.

(To be continued.)

\title{
Biometry and Evolution.
}

W HEN an entirely novel and revolutionary view is put forward by a man of scientific eminence, the critic must endeavour to form a decision between two alternatives, for both of which he must necessarily be, to some extent, unprepared. Either a scientific discovery has been made of such a magnitude as to subvert a whole body of apparently well-founded opinion, or, what is more disturbing still, some incredible error has frustrated in its effect all that we might hope from trained ability, industry, and patient thought. We owe it to science to keep this latter possibility in view, whatever may be the weight of authority which is in the balance.

Under the title of "On a New Theory of Progressive Evolution" (Annals of Eugenics, vol. 4, pp. 1-40) Prof. Karl Pearson puts forward a theory which, as he realises, will be difficult to bring home to the biologist. In his own words, "The intensity of heredity is such that with isolation and inbreeding any individual characteristic, or deviation from racial type, will be gradually emphasised and become a factor of progressive evolution. Thus all organisms if isolated are in a constant state of evolution, and it is only interbreeding and the selective action of environment which preserve a type. In other words, natural selection controls evolution, but the progressive urge is provided by heredity itself."

It is obvious that in this statement.Prof. Pearson is using the word 'heredity' in a sense somewhat different from its popular and biological meaning. There is, however, little occasion for surprise in this, for those familiar with his writings will know that the term is used to cover all the statistical relationships between the measurements of related individuals. What is asserted is that these relationshipsrequire that when a group of individuals, differing, however little, from the mean of their species, is isolated, so that they and their descendants interbreed without further selection, then the mean of this isolated population will continue to depart further and further from the mean of the population from which their ancestors were originally selected. A diagram on p. 10 of the monograph shows this process in detail. The first generation following isolation shows, indeed, some regression towards the mean of the original population and differs from it by only about 70 per cent as much as its parents. In the second generation, however, the mean has progressed to nearly 95 per cent and, thereafter, the successive means actually exceed that of the foundation stock, and increase so rapidly that by the eighth generation the deviation is nearly seven times as great as it was at first.

For the formulæ from which these astonishing results were derived recourse should be had to the mathematical appendix, where, on p. 23, we find that they are the result of applying a certain recurrence formula, based upon a system of formulæ for the correlations between the averages of different groups of ancestors of the same individual; the numerical values come ultimately from three correlations found in human stature, namely, parental correlation 0.50625 , fraternal correlation 0.53367 , and marital correlation $0 \cdot 2804$.

Prof. Pearson has been content to apply his recurrence formula numerically, but it is capable of algebraic solution. It appears that the deviation

No. 3172 , VoL. 126] 
after $n$ generations will be $M$ times the deviation of the foundation stock, if $M$ is given by the formula

$$
M=\frac{a}{b} \cdot \frac{(1 / b-1) !}{\{(1+a) / b-1\} !} \cdot \frac{\{n-2+(1+a) / b\} !}{(n-1+1 / b) !} \cdot 2^{n / 2} .
$$

The formula involves two numerical constants, $a$ and $b$, for which Prof. Pearson's values are $a=$ $0.494155, b=0.55916$. It will be noticed that the progressive evolution deduced from this method depends upon two factors, of which one, $2^{n / 2}$, representing a doubling in every two generations, has perhaps been introduced through an incomplete allowance for the fact that, with bi-parental reproduction, each individual has $2^{n}$ ancestors of the $n$th degree. The remaining factor

$$
\frac{\{n-2+(1+a) / b\} !}{(n-1+1 / b) !}
$$

increases progressively only when $a$ exceeds $b$. This is not so with Prof. Pearson's values, which, if the factor $2^{n / 2}$ were removed, would thus give a progressive decrease, less rapid than, but equally foreign to biological reasoning as, the progressive increase shown by his values. This trouble disappears, however, if $a$ is equal to $b$, as it may well be, if the relatively small difference between Prof. Pearson's values be ascribed partly to sampling errors in the original data, and partly to a second but slighter inexactitude in the process of reasoning by which the infinite series of ancestral correlations is deduced from the three correlations actually observed.

The thesis thus derived theoretically is supported both by the author's own experiments and by a reinterpretation of the experiments of others. $\mathrm{Al}$ - though Prof. Pearson writes strongly, when genetical concepts come into view, it may be doubted if he would much rely upon these two sources of information, if his theoretical deductions were once shaken. The personal observations cited are indeed somewhat meagre. It appears that an experiment started twenty-five years ago with the crossing of toy Pomeranians and Pekinese has been continued since with much inbreeding; the experimenter has "been a good deal puzzled of recent years by a progressive tendency to lengthen the leg". The experiment was not concerned with leg length. "But this very ungainly length of leg has been continually obtruding itself, although I have paid no regard to it in mating." Unfortunately, no measurements were taken, and the skeletons were not preserved, so that it is largely a matter of taste whether or not we share the author's deduction: "Given isolation and inbreeding, say from a single isolated pair, then if both members of the pair differ by excess or defect from typeand this by however small a quantity-their offspring by continual inbreeding will progress for this character, and therefore for all correlated characters. This is the idea that came to me from the long-leg progress of my dogs."

The reviewer feels a particular regret that the data on this case are not fuller, for about eighteen months ago he happened to write, in connexion with the biometric effects of recent selection, "Equally, when, as in the development of toy breeds of dogs, selection has favoured diminished size, we should expect to find an excess of recessives tending to increase the average dimensions ".

R. A. Fisher

\section{Food Preservation.}

$\mathrm{T}$ HE practical value of the numerous researches carried out under the auspices of the Food Investigation Board is clearly shown on perusal of the Report for 1929.* The work on meat deals with the influence of quality and pre-freezing treatment upon the appearance or 'bloom ' of the meat after thawing, with proper conditions for transport, with the changes occurring in rigor, and with the bacteriology of frozen carcasses. The investigations on fruit include researches on wastage in store, on the chemical changes during ripening and senescence, and on variations in resistance to fungal invasion. Work has been carried out on pig products, fish, the causation of corrosion in tins, and on engineering problems of refrigeration.

The extension of the Low Temperature Research Station at Cambridge has been completed; the Ditton Laboratory at East Malling, Kent, for research on the storage of fruit is nearly ready for occupation, and the temporary buildings of the Torry (fish) Research Station at Aberdeen are in use. Special stress is laid in the Report on cooperation with industry ; a combined research with

* Department of Scientific and Industrial Research. Report of the Food Investigation Board for the Year 1929. Pp. 146. (London: H.M. Stationery Office, 1930.) 2s. $6 d$. net. the trade and members of the New Zealand Department of Scientific and Industrial Research and the Australian Commonwealth Research Council is in progress; an exhibit of frozen carcasses of mutton was held at Smithfield, and a small laboratory is maintained at Covent Garden, acting as a liaison with the trade.

As illustrative of the scope of the scientific work of the Board, certain of the researches on meat, fruit, and pig products may be referred to in more detail.

Moran and Smith report that the unpopularity of imported frozen beef is probably chiefly due to its initial poor quality, since the palatability of prime frozen beef compares very favourably with that of prime home-killed Scotch. Another factor of importance is the pre-freezing treatment, since it is during this interval that the changes associated with rigor mortis occur : in this process the consistency of the muscle substance changes, and it appears that the rate of hardening is controlled by the course of the chemical reactions which lead to the post-mortem production of heat. The formation of lactic acid is not directly associated with the hardening. The importance of the rate of freezing, the temperature reached, and the subsequent rate

No. 3172, Vor. 126] 